\title{
O meio ambiente e o futuro
}

\author{
WERNER E. ZULAUF
}

\section{Contexto}

$\mathrm{O}$ MOMENTO ora vivido pela humanidade, geometrizado pelos números cheios, 2000; 500; cada um sugerindo um pacote de séculos, tende a direcionar as reflexões dos seres humanos para os fantásticos conteúdos históricos desses pacotes. A mídia é o principal agente potencializador dessas reflexões, na medida em que pauta a história do Brasil de 500 anos sob os mais variados ângulos, assim como a história no período do cristianismo, outro tema fascinante, no qual cabe desde parte do Império Romano, toda a Idade Média, o Renascimento, a Revolução Industrial, tudo culminando com os incríveis inventos do século XX. É oportuno que se contem essas e outras histórias, mas é igualmente importante que se aproveitem os ângulos retos da geometria da história para olhar para a frente e para forçar reflexões sobre o futuro, abordando outros ângulos do épico Assim caminha a humanidade, mais pelo título do que pelo seu conteúdo propriamente dito.

A Agenda 21, uma das poucas pautas do futuro, é ousada pela abrangência e pelo horizonte de um século. Nunca se planejou para um período tão longo. O grande prazo requer adaptações metodológicas, nas quais, aos planos convencionais de uma a duas décadas, acoplam-se prognósticos e reflexões sobre os grandes temas e suas interfaces setoriais.

Ainda recentemente, diletantes, fazíamos cálculos a partir da população mundial de cinco e meio bilhões de habitantes. Hoje já teríamos ultrapassado os seis bilhões. Quando saberemos o número da assíntota da estabilização? Como será a componente social das políticas públicas daqui a três décadas? É lícito especular e concluir que a degradação ambiental só não é maior porque mais da metade da população do mundo vive à margem da sociedade de consumo? Haverá determinação de, mesmo sob a justificativa da necessidade de ampliar o número de consumidores, promover-se fortemente a ampliação da população com acesso a bens de consumo? Isto será elevar a qualidade de vida? Qual o tamanho do impacto ambiental decorrente da ampliação de cada fração de $10 \%$ de novos consumidores em nível mundial? Os recursos naturais são ou não inesgotáveis? Até a metade do século XXI os oceanos terão subido um metro, inundando milhares de cida- 
des portuárias e turísticas, além de férteis deltas de rios em todo o mundo, por causa do "efeito estufa"? Em que medida a reciclagem economizará recursos naturais não renováveis para as gerações futuras? O automóvel manterá seu fascínio e sua hegemonia como meio de transporte e símbolo de status? Continuará impondo investimentos maciços em vias de transporte em detrimento de outras demandas da sociedade?

\section{Defesa do meio ambiente}

O meio ambiente é o endereço do futuro para o qual haverá a maior convergência de demandas entre todas. Não é necessário realizar estudos muito profundos para se concluir que a qualidade da água se encontra fortemente ameaçada; que o clima tende a se transformar no próximo século por conta do efeito estufa e da redução da camada de ozônio e que a biodiversidade tende a se reduzir, empobrecendo o patrimônio genético, justamente quando a ciência demonstra a cada dia o monumental manancial de recursos para o desenvolvimento científico que a natureza alberga.

A defesa do meio ambiente, conceito que inclui a restauração de ecossistemas, é uma atividade que teve seu desenvolvimento como conjunto de ações ordenadas iniciado em meados do século que se finda e que, para fins didáticos, podem ser agrupadas como segue, em três fases.

\section{Fase pioneira}

A simples percepção de que a humanidade, que já havia ordenado o seu comportamento para limitar procedimentos inoportunos do convívio em sociedade, como a tipificação de crimes, contravenções e atitudes comprometedoras da qualidade da vida em comunidades, ameaçava de forma crescente os recursos ambientais, pelo falso entendimento de que aquilo que não pertencia especificamente a alguém poderia ser utilizado de forma inconseqüente por qualquer um, fez surgir de forma espontânea o movimento ambientalista, simultaneamente em várias cidades de diversos países.

Inicialmente sem maiores fundamentos científicos, protestava-se contra atitudes obviamente predadoras do meio ambiente, usando-se os mais exóticos recursos para chamar a atenção como subir em árvore para evitar a sua derrubada, protestar contra os incômodos pontuais da poluição atmosférica ou direcionar a atenção para as causas de mortandade de peixes etc.

As elites tratavam de desqualificar tais atitudes, rotulando os ativistas ecológicos com os mais variados e pejorativos adjetivos, na medida em que elas pressentiam que a defesa do meio ambiente fatalmente acabaria com 
alguns de seus privilégios e, no mínimo, implicaria em investimentos para controlar os efeitos da poluição, por exemplo.

O protesto contundente e nada ortodoxo, entretanto, foi registrado pelos meios de comunicação, que viam, naquelas atitudes estranhas, no mínimo, matéria de interesse jornalístico. Daí para a assimilação pela sociedade foi um passo natural. Um misto de curiosidade e de concordância com as teses dos ecologistas fez crescer a vontade social de mudar comportamentos predadores por outros com respeito pela natureza, mesmo que, individualmente, essa mesma sociedade ainda não estivesse preparada para efetivamente fazer a sua parte. Muitos achavam que, se os outros melhorassem o meio ambiente, eles, pessoalmente, poderiam continuar a cometer seus pecadilhos ambientais sem dar na vista.

\section{Fase politica e do "enforcement"}

Como vontade social é precursora da vontade política, a questão ambiental evoluiu para um movimento mundial de criação de temáticos Partidos Verde com destaque para o Die Grünnen, na Alemanha. O caso alemão é emblemático, onde a perspectiva de tornar-se parceiro da coalisão de governo seria concreta com a obtenção de apenas 8 a 10\% dos votos, substituindo o Partido Liberal (FDP) como fiel da balança entre os dois grandes partidos (CDU e SPD). Acabou ocorrendo. Hoje o governo alemão é dirigido pela coalisão SPD/Die Grünnen.

No Brasil o Partido Verde (PV) emerge a cada eleição com mais candidatos eleitos, ocupando espaços progressivamente. Os partidos ideológicos de esquerda perderam o discurso diante do inexorável avanço do capitalismo e da globalização, abrindo espaço para um partido temático com discurso claro, objetivo, oportuno e carismático, particularmente entre os jovens.

A pressão dos movimentos ecologistas, amplificada pela mídia, e a inserção do tema no discurso político, a par do desenvolvimento técnico nos institutos oficiais de defesa do meio ambiente e científico nas universidades, levou as autoridades governamentais, em todos os níveis, a editarem leis, decretos, normas técnicas e demais instrumentos de enforcement, isto é, de controle ambiental. No Brasil, aproveitou-se a própria Assembléia Nacional Constituinte de 1988 para inserir um moderno e abrangente capítulo sobre meio ambiente na Constituição Federal.

Ainda no Brasil, houve um notável engajamento do Ministério Público, tanto em nível Nacional (Procuradoria da República) quanto dos estados, pressionando os transgressores da legislação ambiental de um lado e as 
próprias autoridades do Sistema Nacional do Meio Ambiente (Sisnama) de outro, cada um no âmbito das suas responsabilidades ambientais. Dessa ação nasceu a demanda por tecnologias de controle ambiental e de tecnologias limpas de produção.

\section{Fase do mercado}

A demanda por serviços técnicos, por equipamentos de controle e de novos processos limpos teve resposta imediata no mercado, alimentado pela academia e pelos institutos tecnológicos. Não foi difícil. O estado da técnica para atendimento das demandas da produção de bens de consumo estava superaquecido. Alterar rotas para produzir equipamentos de controle ambiental foi muito simples, assim como adequar a engenharia de consultoria e projetos aos novos desafios.

Instrumentos mais sofisticados de mercado surgiram, por exemplo, com as series de certificados ISO-9000 e ISO-14000, pelas quais as indústrias globalizadas não têm outras alternativas senão produzir com competência e com responsabilidade ambiental. Mais uma força na direção da ampliação do mercado verde.

\section{O futuro}

Mesmo o ousado horizonte de um século da Agenda 21 é irrelevante diante da responsabilidade desta geração, transitória para o terceiro milênio, que assiste a uma extraordinária explosão científica e tecnológica e a um aquecimento econômico sem precedentes, infelizmente sem contrapartidas de modelos sócio-econômico e ambiental adequados.

O século XXI vai passar como uma fração de segundo no tempo da existência da humanidade sobre a terra. O que é preocupante é todos desejarem que essa existência tenha a duração não de segundos nessa escala, mas de dias, semanas, anos... Mas como conciliar o enorme potencial de desenvolvimento em escala logarítmica que a base do conhecimento alicerça, com as limitações físicas da superfície do planeta, onde ainda por cima se pretende manter espaços preservados da ocupação antrópica como almoxarifado genético da biodiversidade e reservas de paisagens naturais?

Entre outras respostas, há que se acreditar na capacidade de direcionamento do conhecimento acumulado para soluções nos campos das ciências exatas e biológicas. Nos campos cultural, político e das demais ciências humanas, infelizmente a história mostra os estreitos limites da diplomacia, freqüentemente esgarçados pelas guerras, quando ocorriam incompatibili- 
dades muito menores do que as que o futuro nos reserva. Felizmente os últimos anos criaram um novo ingrediente atenuador de conflitos e que tem alargado o campo de atuação da diplomacia: a globalização da economia. Mas é cedo para afirmar que a paz está selada só porque o comércio criou uma rede de interesses protetora. $\mathrm{O}$ trapezista pode cair fora da rede.

\section{População e desenvolvimento nos campos social e econômico}

A agricultura tem sido competente para frustrar, com a ampliação da produtividade, antigos prognósticos de fome por falta de alimentos. Mas cabe a pergunta: até quando? E quando toda a população do mundo estiver se alimentando corretamente, o que ninguém ousa não desejar, qual a força político-administrativa capaz de evitar que o pantanal seja dragado e que a floresta amazônica seja totalmente derrubada para a sua transformação em pastagens e campos de soja, como é o sonho de parte da elite da região Norte do país?

O desenvolvimento, por todos desejado, é também a única forma pacífica atualmente conhecida de se controlar a natalidade e estagnar o crescimento demográfico. Na Ásia e na África há outros componentes como intransigências de natureza religiosa e cultural, com os quais há que se conviver com paciência e competência para atingir finalmente o nível econômico capaz de sustar, por mecanismos auto reguladores intrínsecos, o crescimento populacional.

Educação e políticas públicas de ampliação de serviços voltados à defesa do meio ambiente são atividades com potencial de geração de empregos que não têm sido exploradas, a não ser de forma superficial no Brasil.

\section{Demanda do consumo}

Sem cometer erros comprometedores do raciocínio aqui exposto, podese afirmar que um terço da população mundial - cerca de dois bilhões de humanos - compõe em sua plenitude a chamada sociedade de consumo; outro terço está à margem do consumo, a não ser para sobrevivência, o que é muito pouco; e um outro terço vive uma situação intermediária, em ascensão ao privilegiado mundo dos consumidores.

Pelos impactos ambientais gerados por produção, transporte, comercialização, uso e descarte dos bens e serviços de consumo, no nível em que ocorrem hoje, particularmente em países emergentes como o Brasil, arrepia a simples extrapolação de tais impactos para uma sociedade em que praticamente todos sejam consumidores vorazes. Mas este é o mecanismo que, 
paradoxalmente, permite, de um lado, a estagnação do crescimento populacional e, de outro, ter-se uma sociedade mais homogênea, portanto mais receptiva às políticas públicas de reciclagem, disciplina individual para a defesa do meio ambiente e consciência coletiva da necessidade de deixar para as futuras gerações condições de vida com qualidade. O pré-requisito fundamental para atingir-se tal estágio é a educação, no seu sentido mais abrangente e, especificamente, a educação ambiental, que tende a ser uma conseqüência natural do processo mais amplo; no Brasil, desde a Constituição de 1988, a educação ambiental é obrigatória em todos os níveis de ensino do país; falta ser obedecida de forma mais efetiva nas escolas e falta, principalmente, $\mathrm{o}$ acesso de todas as crianças e jovens às escolas.

\section{Proteção das águas}

Fala-se muito ultimamente da ameaça de falta de água para as demandas do próximo século e dramatiza-se a questão insinuando que a água, ou a sua falta, poderá ser a causa de guerras no século XXI. A preocupação faz sentido quando se observa o descaso dos governos e da sociedade em geral com o manejo da água. Basta olhar para qualquer córrego urbano para sentir o drama da água, emporcalhada por esgotos domésticos, resíduos industriais e lixo de todas as naturezas. Na zona rural não é muito diferente. Os agrotóxicos são lançados sobre o solo sem o entendimento de que o passo seguinte é a lixiviação desses venenos para os rios, o mesmo ocorrendo com os fertilizantes químicos. Os desmatamentos generalizados concorrem para o assoreamento dos rios, não havendo nem mesmo a obediência a um dos poucos dispositivos legais de proteção dos recursos hídricos que são as matas ciliares. As medidas para utilização racional da água são mais complexas e abrangentes do que possa parecer, mas possíveis como apresentado a seguir de forma obviamente resumida.

\section{Controle dos desmatamentos}

A manutenção de coberturas florestais - mesmo que de matas homogêneas plantadas para fins de manejo econômico - nas encostas de relevo acentuado é a forma mais adequada de reservar-se água no subsolo, regularizando a vazão dos rios.

As florestas nativas são mais adequadas por preservarem outros recursos naturais, particularmente a biodiversidade. Esta, em relação às espécies animais de maior porte, exigem espaços maiores e interligados por corredores florestais. Bosques isolados pouco significam para espécies do topo da cadeia alimentar. 


\section{Políticas de reflorestamento}

O Projeto Floram, desenvolvido há 10 anos no âmbito do Instituto de Estudos Avançados da USP, continua sendo a proposta mais completa de política florestal ecológica, por contemplar o controle do efeito estufa, a manutenção da biodiversidade, a restauração da paisagem, a atividade econômica florestal, a prevenção contra a erosão do solo e o assoreamento dos rios, a restauração da qualidade dos recursos hídricos e a regularização dos fluxos de águas de subsolo e superficial. A essência do Floram é a ocupação de todos os solos deteriorados pela exploração inadequada, dos solos desmatados de topografia irregular, dos solos de pouca fertilidade para a agricultura e dos solos em processo de desertificação, para a sua restauração mediante uma combinação de florestas homogêneas de crescimento rápido (cerca de 60 a 70\%) com reconstituição de matas nativas (de 30 a 40\%), constituindo um mosaico contínuo de cobertura florestal, alternando-se bosques de matas nativas com florestas homogêneas plantadas. $\mathrm{O}$ manejo da floresta homogênea proporciona a sustentação econômica do empreendimento enquanto a reintrodução de matas ciliares expandidas e de matas de encostas, nativas, recompõe a base para a diversificação biológica nos diversos estratos da cadeia alimentar da vida silvestre. Pela visão social que acompanha a postura ambiental do professor Aziz Ab'Saber, foi introduzida no Projeto Floram a componente agrícola de subsistência das populações empregadas na silvicultura. O Projeto Floram foi reconhecido internacionalmente, tendo recebido a medalha (versão ouro) Hopes for the Future for a Sustainable World concedida pela Academia Internacional de Ciências de Munique e pela International Union of Air Pollution Prevention Associations (IUAPPA), pela comissão presidida pelo Prêmio Nobel, professor Yuan T. Lee, do Instituto Senica de Taipei, Taiwan. Em que pese o alto valor da honraria internacional e a simplicidade do enunciado do Floram, o projeto ainda não foi assumido como política pública florestal no país onde foi concebido, embora projetos isolados de formulação próxima ao Floram estejam sendo implantados embrionariamente para compensação de emissões de $\mathrm{CO}_{2}$.

\section{Controle de erosão}

A manutenção da qualidade da água está fortemente associada ao seu regime de escoamento. O combate à erosão promove o controle do assoreamento que, por sua vez, em conjunto com as demais políticas de manejo sustentado de bacias e microbacias hidrográficas, reduz as enchentes às várzeas, que são domínios dos rios. Com enchentes controladas reduzem-se os efeitos catastróficos de arraste de casas, automóveis, madeiras, pneus e de- 
mais entulhos, que acabam ampliando o assoreamento, engatilhando novas enchentes ainda mais dramáticas.

\section{Controle de defensivos agrícolas}

A tecnologia tem atuado a favor da defesa do meio ambiente no que concerne ao combate de pragas, produzindo defensivos agrícolas com princípios ativos de menor vida útil, o que significa menor acumulação desses tóxicos no ambiente. A biotecnologia, especificamente, está indo além, ao produzir predadores biológicos para pragas danosas à agricultura e de espécies resistentes, em que pese que as pesquisas que atuam nesse campo, quando realizam manipulações genéticas, atuam em contextos que ainda não definiram claramente seus balizamentos éticos.

Qualquer que seja o desfecho da evolução das técnicas de produtividade agrícola, hoje, o uso de produtos químicos é um dos sérios fatores de deterioração da qualidade dos recursos hídricos. É lícito ser otimista quanto ao futuro no que concerne à poluição química por defensivos agrícolas, mas há que se adotar cautela quanto aos efeitos da manipulação genética na biotecnologia.

\section{Fertilizantes agrícolas}

Quanto ao uso de fertilizantes químicos, os procedimentos futuros são menos complexos do ponto de vista tecnológico, na medida em que as plantas necessitam de macro e micronutrientes e o solo tem capacidade limitada para o suprimento desses insumos. Não há muito o que inventar. Praticamente tudo o que deve ser feito está nos livros sobre adubação orgânica e adubação organomineral do professor Edemar José Kiehl, da Escola Superior de Agricultura Luiz de Queiroz (ESALQ), de Piracicaba (SP).

O que realmente deve ocorrer é uma transformação ideológica (ideologia no seu sentido mais amplo e não apenas no sentido político) nas escolas de agronomia, hoje dominadas pela receita fácil de aplicação de fertilizantes químicos. Particularmente em solos pouco argilosos, a falta do elemento coloidal ligante pode ser compensada pela introdução de húmus, encontrado tanto na turfa quanto no composto orgânico.

Como fonte de matéria orgânica para produção de composto é oportuno mencionar que a metade de todo o lixo urbano produzido no Brasil é matéria prima de excelente qualidade para compostagem. Somem-se a isto os resíduos da indústria de alimentos, também rica em insumos compostáveis e resíduos vegetais e animais das mais variadas naturezas. 


\section{Controle da poluição das águas}

Os contornos definidos pelos itens mencionados reúnem conteúdos que esboçam o tamanho dos desafios a serem enfrentados para assegurar água em quantidade e qualidade para o futuro. As tecnologias para o tratamento da água ou, melhor, para evitar que ela seja contaminada, existem e desenvolvem-se mais pelas leis de mercado do que pelas leis do Diário Oficial. O fantasma da falta de água para o futuro é real e deve perturbar o consciente e o inconsciente coletivos de forma permanente para alavancar decisões político-administrativas, tanto da iniciativa privada como e, principalmente, dos governos; estes por suas obras ou políticas públicas são, de longe, os maiores responsáveis pela degradação ambiental em geral e das águas em particular.

- Da atividade agroindustrial. A agroindústria é atividade com forte potencial de poluição orgânica da águas, o que significa que uma usina de açúcar e álcool ou uma fábrica de papel e celulose, por exemplo, podem matar todos os peixes de um rio numa extensão de muitos quilômetros, situação que se agrava quando não é apenas uma usina, mas diversas ou muitas, em função da vocação econômica de um estado ou região. O rio morto costuma ressuscitar a jusante depois que a atividade microbiológica do próprio rio atuou e digeriu a carga poluidora que, nesse caso, costuma ser predominantemente orgânica, ou seja, biodegradável. Ficarão seqüelas certamente, mas a pior conseqüência é a inadequação das águas do rio para usos múltiplos nos trechos poluídos.

- Da indústria em geral e química em especial. Os setores químico, petroquímico e de fertilizantes são exemplos de indústrias cujos resíduos incorporam componentes tóxicos ou transformadores das características da água que, por não serem biodegradáveis, são de difícil digestão, podendo acumular-se na cadeia alimentar e causar danos pela ingestão de peixes ou crustáceos. É clássico o caso da doença de Minamata. A contaminação com mercúrio descarregado por uma indústria de soda provocou reações bioquímicas no lodo do fundo da baia de Minamata, Japão, transformando o mercúrio metálico em metilmercúrio, assimilável pelos organismos bentônicos. À medida que os peixes que se alimentaram de outros peixes ou crustáceos atingiram dimensões maiores, aumentaram a concentração de mercúrio no tecido orgânico. Depois de mais de uma década começaram a surgir os sintomas na população que tinha nos peixes sua principal fonte de proteínas. Deformações nos adultos e má formação congênita adqui- 
riram dimensões de epidemia. Depois do alerta, outros casos foram detectados, inclusive o da enseada dos Tainheiros em Salvador, na nossa Bahia. Algumas vezes, como no caso do aumento da vazão dos rios pelo aporte de mais água dos afluentes, os contaminantes são diluídos, reduzindo-se aparentemente seu poder de interferência no ecossistema. É o que ocorre no rio Tietê, fortemente contaminado na região metropolitana de São Paulo, mas que a jusante de Barra Bonita aparenta ser um rio limpo. O que não aparece é a quantidade crescente de lodo acumulado no fundo das represas de Santana do Parnaíba, Pirapora, Rasgão, Salto e Barra Bonita, para citar apenas as que contêm os coquetéis mais agressivos de lodos, verdadeiras bombas de veneno prontas para serem detonadas em ocorrências climáticas ou manobras hidráulicas não comuns.

- Dos esgotos domésticos. A forma mais escandalosa de poluição das águas é a que se dá no ambiente urbano, onde vive a maioria da população, que vê e sente o mau cheiro dos córregos poluídos e que sabe que cada habitante, pessoalmente ou por atividade econômica da qual participa, contribui para aquele quadro degradante sem que, via de regra, esboce qualquer gesto de revolta. Este conformismo irritante refletese nas prioridades de investimentos dos governos, que não priorizam investimentos no setor de coleta e tratamento de esgotos por serem pouco cobrados pela sociedade; e quando investem, o fazem de forma incompleta.

O caso do Parque do Ibirapuera em São Paulo é bem representativo dessa incompetência: a bacia de drenagem do córrego do Sapateiro é totalmente urbanizada (parte do bairro de Vila Mariana) e suas ruas são totalmente servidas por redes de coleta de esgotos e (separadamente) de coleta de águas pluviais. Todos os esgotos gerados deveriam ser canalizados para a rede de esgotos, entretanto, parte apreciável dessas imundícies acabam nos dutos de águas pluviais e daí, no Sapateiro, que, por sua vez, deságua no lago do Ibirapuera, comprometendo a qualidade da água do lago e, por via de conseqüência, a estética de todo o belo parque. Mesmo tratando-se do cartão postal da cidade, idiossincrasias políticas e incompetências técnicas por parte das autoridades estaduais de saneamento falam mais alto e o quadro dramático eterniza-se. Além da agressão estética aos usuários do parque, este caso é uma afronta à cidade e um fator de preocupação a mais: se nem no Ibirapuera as autoridades se entendem, o que esperar do saneamento no resto da cidade e, em especial, na pobre, abandonada e acuada periferia distante? 
O caso anterior não só não é o único, mas reflete uma insensibilidade gritante. As obras de saneamento não são vistas como empreendimentos destinados a limpar os rios; são apenas obras, com investimentos vultosos, que se esgotam em si mesmas. O importante é conseguir o dinheiro, contratar uma empreiteira generosa, enterrar os dutos, fazer as medições dos serviços e pagar! Conectar os esgotos das casas e dos prédios de apartamentos é um detalhe secundário. Será feito oportunamente quando o proprietário do imóvel requerer os serviços, o que, via de regra, não ocorre. Em Santos (SP), apesar de a cidade estar servida há muitas décadas com redes coletoras de esgotos, os canais continuam imundos, a ponto de as autoridades, para reduzir a poluição das praias, optarem por uma solução pouco ortodoxa: captar a água dos canais e descarregá-la, por grandes ralos, no interceptor oceânico que passa abaixo dos canais com capacidade ociosa. Em Joinville (SC), ocorre o mesmo, discutindo-se a conveniência de barrar o córrego Mathias e demais afluentes imundos do rio Cachoeira e descarregálos nos interceptores do ocioso sistema de esgotos da cidade, obra que consumiu montanhas de dinheiro ao longo das últimas três décadas, sem produzir resultado prático algum em termos de despoluição do rio Cachoeira, da lagoa de Saguaçu e da baia da Babitonga.

As obras de saneamento urbano são caras e impactantes na vida das cidades durante sua construção. É comum ouvir-se que os prefeitos não gostam de executá-las para não sofrer o desgaste político durante a execução e porque, quando concluídas, ninguém se lembra delas. A inferência é precipitada e simplória. Retrata a pobreza técnica da assessoria de comunicação social da prefeitura. Não existe obra com mais ou menos apelos em termos de comunicação social. Existe sim, maior ou menor competência dos comunicadores sociais. Qualquer obra, desde que necessária, é massa crítica política capaz de projetar o administrador que tomou a decisão de implementá-la. A escolha de comunicadores competentes é outra história.

Até aqui, neste item, tratou-se da poluição direta por esgotos. Olhando para os próximos séculos do milênio que vem chegando, deve-se enxergar muito mais. Não basta tratar os esgotos. O produto final ainda carrega apreciável carga de componentes que a ciência começa a identificar e que, a longo prazo, podem afetar o meio ambiente e a saúde pública. Há que se pensar seriamente em recirculação de águas tratadas para usos secundários, como em redes de irrigação de parques e jardins, usos industriais ou mesmo domésticos menos exigentes em termos de qualidade. As águas pluviais urbanas captadas nas redes próprias deverão igualmente ser tratadas, já que carreiam contaminantes estocados nos telhados, calçadas, ruas e sarjetas. A água dos rios e lagos deve ser a mais limpa das águas, para que possa exercer 
seu papel ecológico fundamental, que é a manutenção do estoque genético da vida aquática, não apenas em quantidade, mas também qualitativamente, em cada rio ou lago, pois não existem dois ecossistemas iguais. Cada um tem suas características em função da altitude, temperatura da água, vazão, turbulência do fluxo, aporte natural de nutrientes, interação com as frações territorial e atmosférica do ecossistema em que está inserido etc.

Observa-se que a atitude dos nossos descendentes com relação aos rios, lagos, mares e oceanos deverá mudar mais ainda do que tem mudado, por exemplo, a atitude da geração atual com relação à vida silvestre. Quem imaginaria, há apenas várias décadas, que os safáris de hoje seriam apenas para observar e fotografar animais silvestres em seu habitat natural? E que por isso mesmo estariam sendo massificados com um mínimo de impacto sobre a vida dos animais?

- Dos resíduos sólidos. A disposição final de resíduos sólidos, aí incluídos os resíduos das atividades domésticas, urbanas, rurais, comerciais, industriais e de serviços de saúde, com características sólidas, pastosas ou mesmo líquidas quando tóxicas é, em conjunto com o problema dos esgotos, o maior problema ambiental urbano não resolvido no país e, pode-se generalizar, em grande parte do mundo.

Muito menos oneroso em termos de investimentos do que a solução para os esgotos, mesmo assim, pouco tem sido implementado no Terceiro Mundo (se é que essa expressão ainda faz sentido...) nesse campo. A causa é uma só: ausência de vontade política por falta de vontade social. Assim como a população das cidades convive com os rios sujos, convive também com terrenos baldios e beiras de ruas da periferia entulhados de lixos das mais variadas naturezas, onde não faltam resíduos tóxicos de alta periculosidade. Todos esses lixos acabam arrastados ou, pelo menos, lixiviados para os córregos e rios urbanos, ampliando o caldo diabólico de venenos das águas.

A solução passa pela adoção dos novos conceitos de reciclagem, descritos adiante. À medida que a gestão dos resíduos sólidos for adotada em bases econômicas e técnicas adequadas, cessa também o comprometimento das águas causado pelo arraste e pela lixiviação de lixo. Este texto somente permite que se aborde o problema com tamanho otimismo porque não há limitação de tempo para a implementação das medidas propostas. É sempre oportuno ter em mente que se falar aqui em décadas, séculos e até no próximo milênio, significa que tais compartimentos de tempo poderão ser necessários para a implementação das soluções propostas, caso não se tenha competência para mudar a cultura predadora da sociedade. 


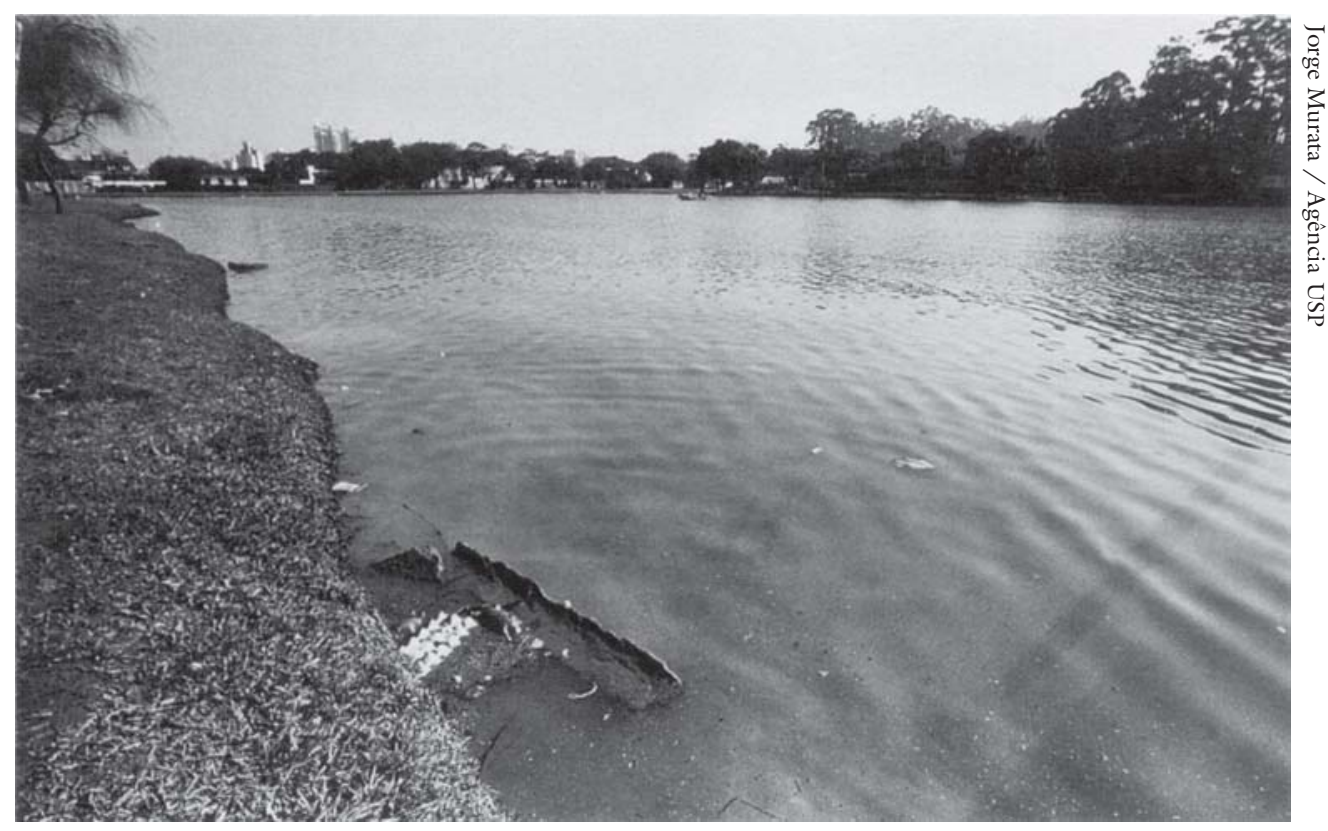

Se nem no Ibirapuera as autoridades se entendem, o que esperar do saneamento no resto da cidade e, em especial, na pobre, abandonada e acuada periferia distante?

\section{A reciclagem}

O mundo gera mais de três milhões de toneladas de lixo por dia, das mais variadas naturezas, sem contar os resíduos industriais e rejeitos de mineração, praticamente incalculáveis. Mesmo os mais estanques e corretos aterros sanitários norte-americanos, quando se observa o conteúdo dos coletores descarregando o lixo nas frentes de operação, são atestados de incompetência das sociedades atuais e de seus governos no trato do problema.

Muito já se tentou em termos de abordagem desse gritante problema. Cunhou-se até a expressão dos "3 R": Reduzir, Reutilizar e Reciclar. Bate-se muito na tecla do reduzir. Talvez seja pouco produtivo, à medida que a sociedade de consumo tende a se ampliar e o descarte de lixo seja uma conseqüência natural. Aliás, se o consumo de bens e serviços regredir, apenas como hipótese, é bom refletir o que isto significaria em termos de redução adicional de postos de trabalho, além dos que já estão sendo cortados pela racionalização proporcionada pelo desenvolvimento tecnológico e que a competição e a busca permanente de ganhos de produtividade promovem. Quanto aos dois outros "R", na verdade podem ser tratados como um só: reciclagem.

A reciclagem é o conceito mais promissor e o fato mais importante que surgiu no setor de meio ambiente nos últimos anos. Visto de forma pragmática, é a forma de conciliar as tendências mundiais de globalização, 
que embute a tendência de universalização da sociedade de consumo e, por via de conseqüência, a ampliação da geração de resíduos, com a atividade econômica do processamento de resíduos.

Não é por acaso que as grandes feiras mundiais de meio ambiente de Munique, Colônia e Atlanta, apenas para citar três delas, oferecem a cada ano novas e criativas tecnologias para a reciclagem dos mais variados componentes do lixo. A solução para este imenso problema começa a entrar na fase de mercado (ver item Fase de mercado).

Com base em mais de 30 anos de observação da evolução de propostas de soluções para a destinação final do lixo, no país e no mundo, administrando diretamente e observando os erros e os acertos de outros administradores e, principalmente, colocando esses conteúdos todos no contexto econômico moderno, surgiu o conceito de macrorreciclagem, a seguir descrito, contribuição do autor para o encaminhamento de profundas mudanças na gestão dos serviços de limpeza urbana.

A macrorreciclagem parte do princípio que todo o lixo deve ser processado com vistas à redução dos descartes em aterros, obedecendo, entretanto, a regras de mercado.

O princípio básico desse conceito é o acondicionamento do lixo no domicílio com diferenças sutis em relação ao que já se pratica em muitas cidades, mas fundamentais para os propósitos da macrorreciclagem, que é separar a matéria orgânica úmida (restos de alimentos, de preparação de alimentos, lixo verde de podas etc.) do chamado lixo seco (embalagens, metais, plásticos, vidros, borrachas etc.) em dois recipientes distintos.

A coleta seletiva simultânea é o próximo passo, quando os resíduos separados são transportados na mesma viagem do coletor, mas em compartimentos separados. O terceiro passo é o processamento das duas frações (orgânica e seco) separadamente no Centro de Reciclagem e Destinação de Resíduos (CRDR). Observe-se que se busca não misturar matéria orgânica úmida com lixo seco para que uma fração não contamine a outra, o que permitirá a produção de composto orgânico da melhor qualidade, assim como melhor triagem do lixo seco, na medida em que este não estará impregnado de pegajosos restos de alimentos.

A partir daí cada caso será tratado em função das suas peculiaridades, da disposição das autoridades em empregar mais mão-de-obra ou de mecanizar mais os processos, o que requer maior aporte de capital no início, mas gera ganhos de produtividade. $\mathrm{O}$ desempenho empresarial deverá ser cotejado, em cada caso com o benefício social e, obviamente, com a qualidade 
da solução ambiental, esta vista por todos os ângulos. A solução não poderá causar impactos nem de poluição nem de incômodos para a vizinhança, devendo contudo contemplar ao máximo a reciclagem, na medida em que esta é o grande legado que passará como modelo para as gerações futuras.

Como reciclagem entende-se não apenas a triagem de materiais como latas de ferro e alumínio, vidros, PET, papel, papelão, tetrapack etc., mas também a produção de composto orgânico para uso como fertilizante agrícola, a extração de energia (Biogás) pela fermentação anaeróbia da matéria orgânica (primeira fase da compostagem), apropriação da energia termelétrica do rejeito do lixo seco (só para cidades muito grandes), reciclagem de pneus, baterias e pilhas, além de embalagens de defensivos agrícolas da área rural do município.

Não basta, entretanto, uma boa concepção técnica para a grande virada tecnológica da macrorreciclagem. O novo conceito também trás no seu bojo uma proposta institucional, baseada na concessão dos serviços por períodos mais longos, 10 a 20 anos, prorrogáveis, para que o concessionário, que terá de fazer investimentos vultosos para processar industrialmente os resíduos e colocá-los no mercado, possa gerenciar o processo em condições de retorno compatíveis com outras oportunidades de negócios. O aspecto tributário também contém inovações, à medida que a taxa de lixo passa a ser cobrada pelo órgão de água e esgotos (outra opção é a cobrança junto com a energia elétrica), mediante equação de correlação (estabelecida estatisticamente em cada caso) entre o consumo de água de uma residência e a geração de lixo dessa mesma residência, assim como já é feito para a cobrança dos serviços de esgotos sanitários. O órgão de água e esgotos repassa a parcela da taxa de lixo para a concessionária de limpeza urbana, mediante retenção de fração para a cobrança dos seus serviços administrativos. Quando os serviços de água e esgotos são administrados por empresa ou autarquia municipal, a solução torna-se ainda mais simples: esse órgão passa a exercer, por delegação da prefeitura, a função de poder concedente, contratando e fiscalizando o concessionário da limpeza urbana.

O primeiro plano diretor específico e completo de um serviço de macrorreciclagem acaba de ser concluído para o município de Jaraguá do Sul, extensivo a outros quatro municípios vizinhos em Santa Catarina, onde, além dos serviços de coleta de lixo, também farão parte do pacote de serviços a varrição de logradouros públicos, a limpeza e lavação específica de feiras, as remoções especiais de lixo verde (podas e resíduos de manutenção de jardins e parques públicos e particulares), a manutenção de galerias de águas pluviais, a remoção de resíduos tóxicos da zona rural, os resíduos do comércio, da indústria (fração expressiva neste caso específico) e de serviços 
de saúde. O processamento para a reciclagem de todos esses resíduos no CRDR e a harmonização paisagística desse Centro de Reciclagem e Destinação de Resíduos serão realizados num amplo parque de mata atlântica com dois terços da área total como buffer zone e apenas um terço como espaço operacional, ocupando integralmente uma bacia hidrográfica até os altos divisores de águas.

\section{Conclusão}

Existem condições tecnológicas e uma razoável consciência coletiva da necessidade de aplicação dessas técnicas, mediante planos, programas e projetos para desviar o caminho da humanidade da rota de colisão com o entulho gerado pela irresponsabilidade coletiva de raízes históricas e culturais dessa mesma humanidade.

A angústia dos estudiosos desses problemas relaciona-se à lentidão das decisões político-administrativas destinadas a estimular as práticas de mecanismos de reversão da síndrome do colapso ambiental. A velocidade de reação e as decisões desencadeadoras dos processos corretivos e preventivos não acompanham o galope da depredação da base de sustentação da vida provocada por comportamentos coletivos inconseqüentes.

Se a vontade social é formadora da quase inexistente vontade política ambiental, há que se investir com criatividade no processo de tomada de consciência, mediante forte dramatização, atraindo a atenção da mídia, menos para reafirmar o que já foi exaustivamente denunciado, e mais para destacar o insubstituível papel da mídia na formação da vontade social. Quanto mais for possível acelerar o processo de transformação comportamental com relação ao meio ambiente, menor será o lamento, quando vierem a ocorrer as catástrofes engatilhadas, por não terem sido evitadas a tempo.

Werner E. Zulauf é engenheiro civil e sanitarista, consultor ambiental e ex-presidente da Cetesb. 